\title{
Book review for International Journal of Wellbeing. Estes, Richard J., and M. Joseph Sirgy [eds] (2017) The Pursuit of Human Well-Being: The Untold Global History. Dordrecht: Springer
}

\author{
Neil Thin · Margarita Tarragona $\cdot$ Paul Wong · Rebecca Jarden · Jonathan \\ Bartholomaeus · Aaron Jarden ${ }^{1}$
}

\section{Synthetic overview}

It's hard enough to summarise an individual's diverse experiences of wellbeing coherently, let alone summarise a nation. It's a whole lot harder to offer comprehensive coverage of objective and subjective wellbeing worldwide, and harder still to combine this with historical depth and detailed cultural analysis. This collection therefore wins the prize for being the most ambitious collection on wellbeing to date.

This is an immensely important milestone in the global cultural history of wellbeing, and it will be a superb resource for anyone wanting a comprehensive global overview of philosophies, concepts, and socio-economic and political histories relating to wellbeing, as well as a rich source of basic information on contemporary objective and subjective indicators. The editors have done an excellent job in asking good questions and finding scholars who can answer them. Many of the authors are from the regions they write about, and together they represent an impressive diversity of disciplines including social policy, sociology, history, political science, psychology, religious studies, cultural anthropology, and economics.

The inclusive approach to sources has been particularly impressive, allowing wide-ranging use of humanities and popular culture that enriches the scope and depth of wellbeing research. The editors offer a humanistic and dynamic definition of wellbeing as 'central to the process of becoming a more fully developed human being' (p. 3). This presupposes certain uniquely human qualities - such as spirituality and the quest for meaning - as essential for both our humaneness and wellbeing.

Although it is in some respects refreshing to see various conceptual approaches to wellbeing in the different chapters, the collection might have been more coherent if the editors had promoted a stronger overarching conceptual framework. Most chapters look at objective living standards, physical life outcomes and subjective experience. But distinctions between these aren't always clarified, and there are frequent slips between information on resources and living conditions to information about people's subjective attitudes towards these. From one paper to

\footnotetext{
${ }^{1}$ Neil Thin (Editorial overview and chapters 4,11,12,13); Margarita Tarragona (chapters 2,5,8,15,16); Paul Wong (chapters 1,3,6,10); Aaron Jarden (chapter 20); Jonathan Bartholomaeus (chapters 9,19); Rebecca Jarden (chapters 14,18).
} 
the next there is no predictability concerning the indicators used - no consistent coverage of things like income, violence, peace, democracy, education, health, longevity, gender relations, hedonic wellbeing, or life satisfaction.

In the Introductory chapter, p.6, the editors say they asked contributors to assess gains over time in 'personal and collective well-being'. This is an important but elusive distinction that has rarely been clarified in wellbeing scholarship. But there's no robust analytical treatment of this distinction even in the introductory chapter, although they do discuss several interactive social factors such as benevolence, forgiveness and gratitude. In chapter two (Michalos and Weijers) there is interesting discussion of Enlightenment (Smith, Rousseau, and Jefferson) and views on the trade-offs between private and public happiness (pp.46-49). It might have been helpful if all authors had been encouraged to explore regional manifestations of this kind of distinction.

More importantly, from the start the editors avoid any distinction between means, satisfaction with means, and ends - a basic threefold distinction that ought to be fundamental to any plausible account of wellbeing. Both the introductory chapter and several regional chapters seem wilfully to mingle information on conditions, processes, and outcomes. The editors assert that 'health, education, income, and wealth distribution' are 'considered to be core elements of well-being' (p.7). Some things, of course, like health, knowledge, and happiness, have both intrinsic and ultimate value. However, it surely does not help our understanding of wellbeing to use terms like 'economic wellbeing' and 'educational wellbeing' which so clearly confuse wellbeing with the conditions and processes that may or may not lead to it.

Arguably, too, the collection as a whole could have paid more attention to aspects of human life that make the pursuit of wellbeing so challenging. Just as medical research pays heed to the physically dangerous environment of bacteria, viruses, and toxins, so wellbeing scholars need to recognize subjective and objective sources of adversity. Humans live in a dangerous environment full of objective natural and human-made threats and inevitable suffering, as well as generating mental responses that can make matters worse as well as better. Although the editors declared that they approached the task of editing this volume without any assumption regarding the nature and conditions of wellbeing, their writing indicates otherwise. In fact, it is virtually impossible for anyone to talk about wellbeing without some implicit or explicit models of wellbeing.

Some of the chapters struggled to offer clear analytical insights into the factors that influence wellbeing, and concerning the culturally embedded experiences of wellbeing. The implicit initial premise is that huge regions - most of which have colossal and culturally diverse populations are a useful unit of cultural analysis. Although most chapters pay more detailed attention to subpopulations, the overall the impression is that regional generalisation is assumed to provide an interesting antidote to universalistic treatments of wellbeing. Yet perhaps the more interesting forms of cultural contrasts and distinctiveness are to be found in quite different kinds of cultural unit: countries; ethnic groups; interest groups; leisure clubs; gender; age; religious minorities; businesses; and the cultural attitudes and social processes associated with sports and academic disciplines.

Several authors have in effect adopted a posture of principled non-evaluation: they offer richly detailed descriptions and analyses of the cultural patterns in conceptualisations of wellbeing and prescriptions for good behaviour, without attempting to comment evaluatively on whether these have made people's lives go well or badly. We learn a lot about how some people (mainly elite literati) have thought about wellbeing and virtue around the world in various eras, but we learn very little about the implications of that thinking for how people actually pursue wellbeing, or how well they live. 
Forgivably, given the scope and ambition of the collection, there is also some quirky structuring and sequencing. The introduction is followed by three regional chapters, then one on Islam, and then - bafflingly - a chapter on measurement followed by ten more regional chapters with two more thematic chapters before the conclusions. There's no obvious rationale for the selection of the three thematic chapters, and it's disappointing that there's no overall treatment of the wellbeing of special categories of people such as children or old people. Equally strange is the idea of having two chapters on South Asia in separate parts of the book (the earlier one is on 'India' but covers South Asian history), and putting seven chapters in between the one on SubSaharan Africa and the one on North Africa. Instead of emulating this odd procession, we'll tell you first about the three theoretical chapters, then the three thematic chapters, and the rest is about the regional chapters.

\section{Theoretical chapters}

Estes attributes four basic elements of wellbeing - 'peace, personal satisfaction, happiness, and wellbeing' - to 'personal reflection and interpersonal exchanges.' A humanistic approach of this sort might also have included other contributors to wellbeing such as personal development, character education, and self-transcendence as other. It is not clear, however, that Estes' emphasis on the 'here and now' is warranted. Numerous wellbeing scholars have noted that valuable aspects of wellbeing may be oriented mainly to the past or to the future.

In Chapter 6, on wellbeing measurement, authors Sirgy, Estes, and Selian argue that good historical information is available but that quantitative data are more limited. The global wellbeing measures often lack a component of meaning, which has been shown to be central to wellbeing. Some data have indicated that people in poor countries report a stronger sense of meaning.

A complete picture of wellbeing needs to provide both subjective and objective measures of the dark side of human existence. Considering war-ravaged countries and the refugee crisis, such overwhelming evils and miseries makes it very difficult for people to experience wellbeing. It will take considerable fortitude and endurance to maintain human dignity. The objective misery indexes can include suicide rate, clinical depression prevalence rate, incarceration and execution data, pollution index, poverty rate, discrimination level, violence data, etc. The subjective misery indexes can include self-rating on stress levels, depression, anxiety, and perceived stress. The wellbeing data can be best interpreted in terms of misery index. Death attitudes are importantly related to wellbeing. Spiritual wellbeing is another component that deserves consideration. A complete model of wellbeing can be obtained by using a regression model that employs both positive and negative objective conditions to predict psychological wellbeing. This represents a mature happiness, which is more stable and more enduring because it is based on the reality of suffering.

The final overview chapter reviews patterns in national and regional wellbeing findings reported throughout the book, in particular in Parts III and IV. This highlights the ambition of this book's comprehensive treatment of wellbeing, noting major national, regional, and international changes:

(1) philosophical advances in wellbeing; (2) global advances in population; (3) global advances in health; (4) global advances in education; (5) global advances in income and poverty reduction; (6) global advances in social welfare, in particular, the steadily increasing levels of income security provided to the world's growing population via income security programs and other publicly and privately financed social initiatives; and (7) global advances in subjective wellbeing. 
While these components relate to wellbeing, this last theme on subjective wellbeing is where most of the fruit of the chapter lies. As a wide-ranging summary of many of the pertinent points described in previous chapters, this chapter also provides concluding commentary about the major changes in wellbeing experienced by the majority of people residing in various regions of the world.

\section{Thematic non-regional chapters}

There are three chapters organized around cultural themes (Islam, women, and technology). Awkwardly, there is no sign of any rationale for choosing just these three. The imbalance between the very comprehensive coverage of the regional chapters and the meagre and tokenistic coverage of wellbeing themes is arguably an important weakness in the collection. The potential diversity of thematic chapters could have been limitless, but the structure of the collection would have made a lot more sense if they had either solicited a much more diverse set of thematic chapters, or else simply addressed crosscutting themes within the overview and regional chapters.

The chapter on Islam is the only one to focus on the wellbeing implications of a specific religious tradition, although several of the regional chapters have something to say about religions. One quarter of the world's population is Islamic (a proportion that is rapidly growing) and Islam doesn't fit into any one part of the world, although the same could be said of all major world religions. Mohsen Joshanloo argues that in Islamic beliefs and philosophy, wellbeing is not defined in terms of subjective states or emotion. Instead, to live well is to obey strict religious precepts that help solve the conflict between the innate tendency for good and the "devilish" aspects that all human beings have. Tackling the contemporary and historical complexity and diversity of Islam, he notes that traditional Muslim philosophers were influenced by Greek thought and valued rationality as the way to understand God, whereas Sufis believe that only though the heart can human beings contact God. Despite their diversity, Islamic notions of wellbeing are all tied to religious regimes prescribed in the Qu'ran.

In chapter 18, Elizabeth Eckermann sets out to document the 'global progress of women', offering a narrative of the gradual improvement in women's wellbeing across history. The historical development of international goals for gender equality and empowerment of women, and of measures of women's wellbeing, has been very diverse. Key events of this historical journey are illustrated in a timeline extending from 300 BCE to 2015. The international coverage of this chapter includes key events in India, France, New Zealand, Bhutan, Egypt, and Kuwait. These events highlighted challenges and opportunities for improving women's wellbeing, and influenced gendered understandings of individual and collective wellbeing. For example, matrilineal societies, such as the Minangkabau in Sumatra and the Mosuo from southwest China, are explored in relation to their impact on the status of women. The chapter is an engaging and informative narrative drawing strength from historical visionary advocates of change, exploration of historical landmarks, and the worthy quest to document women's refusal to accept the status quo.

Chapter 19, on technology, is subtitled 'Transformative Market Phenomena Over Time'. Authors Audrey N. Selian and Lee McKnight thereby announce the economistic emphasis of their approach. They discuss the empirical, philosophical, socioeconomic and developmental facets of technology and their impact on the evolution of wellbeing. The chapter proposes that there is a strong correlation or reciprocal relationship between the creation, utilization and dissemination of technology, all of which are linked to human development and therefore wellbeing. The authors use the Human Development Index (HDI) metrics of life expectancy, 
literacy, school enrolment, and income to operationalise the concept of wellbeing. They provide strong and clear arguments for the positive influence of technological progress on wellbeing throughout history. A well balanced discussion is presented as it is acknowledged that technology and innovation can have both positive and negative influences on human development and wellbeing. This chapter will be beneficial for anyone looking to understand how technology shapes human experience.

\section{Regional chapters}

The bulk of the collection (14 chapters) focuses on regional histories. In their chapter on western historical traditions of wellbeing, Alex Michalos and Daniel Weijers offer a thorough and engaging examination of the concept of human wellbeing and its pursuit in the Western world from the 8th century BCE until today. They present the views on wellbeing of ancient Greek philosophers like Plato, Aristotle and Epicure; the religious perspective on what is a good life, particularly within Christianity; the Enlightenment, Utilitarianism, and the pursuit of meaningful goals; and, most recently, the debate about wellbeing as a public policy issue. They examine the roles of virtues, pleasure, harmony with oneself and society, wealth and power, spirituality and public good as important elements of Western conceptions of wellbeing that have had different salience at various points in history. Particularly helpful is their integration of the subjective and the objective dimensions of the quality of life, offering a conceptual matrix to understand wellbeing and they invite us to be aware of the risks of both the 'Fool's Heaven' (having a positive perception of negative objective conditions) and a 'Fool's Hell' (failing to appreciate a positive objective quality of life).

Chapter 3 on East Asia, by Shawn Arthur and Victor H. Mair, has some significant weaknesses. For example, it misses some important recent references, and there is a rather questionable description of wellbeing in China without any supporting evidence (p. 60). A great deal of research has demonstrated that self-determination is essential for wellbeing, but corruption in China is notorious. According to the recent Human Freedom Index, China ranks near the bottom, and human rights organisations continue to find evidence of continuing abuse in China.

The second chapter on East Asia, chapter 10 by Takashi Inoguchi and Richard J. Estes, paints a somewhat rosy picture of this region, considering the oppressive regimes in North Korea and China, and the lack of freedom and self-determination of their people. There is enough objective evidence to question whether people in North Korea and China actually experience 'high levels of self-assessed wellbeing'. Poverty, trauma, and human rights violation all affect wellbeing, especially in North Korea. Another concern is the lack of critique regarding self-rating scales in cross-cultural comparisons and the possibility of response biases due to cultural factors or due to perceptions of public surveys among people living under despotic governments. Also, some of the graphs (e.g. Fig. 10.22) are difficult to read.

The Africa chapter, by Valerie Møller and Benjamin Roberts, is unsurprisingly the most contemporaneous, as the historical records for Africa are meagre and shallow compared with most other parts of the world. They emphasise that given the persistence of widespread poverty in this region, wellbeing assessment continues to focus on basic needs. In terms of self-reported life satisfaction, Africa is by far the unhappiest part of the world, with few sub-Saharan countries scoring above the midpoint. Nonetheless, self-reported 'affect balance' reports (positive versus negative emotional experience) are overall positive for Africa, begging the question (not discussed in this chapter) of whether Africans are affectively optimistic and evaluatively pessimistic, or whether they just understand the life satisfaction scale differently. Since they also 
note that Africa is 'one of the most religious regions of the world' (p.195), it is also possible that religious belief generate optimism at the same time as religious conflicts (endemic in many parts of Africa) generate pessimism. Be that as it may, in terms of sheer survival the authors note the spectacular and rapid gains in African longevity with life expectancy doubling in a couple of generations, despite prevalent warfare and epidemics such as HIV/AIDS.

In the 21 countries of the Middle East and North Africa, according to authors Habib Tiliouine and Mohammed Meziane, there is great cultural and developmental variety. Exploring the region's complex history the authors also note the complexities of the present situation, since many countries experience persistent conflicts. Sadly, most of the countries of the region are unstable and their social conditions are deteriorating. As shown on the "Misery Index", several are experiencing collective misery, and they show low levels of happiness in the World Happiness Report. They also have high scores on the Negative Experience Index, that measures levels of sadness, stress, anger, physical pain, and worry. There is widespread corruption and low levels of trust in institutions. Despite these disturbing figures, the authors point out that the region has made important gains in some objective quality of life indicators, such as life expectancy and education, and they are hopeful that the rest of the world can contribute to the positive social changes that are occurring in this region.

The India chapter, by anthropologist Isabelle Clark-Decés and Sanskrit scholar Frederick Smith, covers classical and modern periods and some of this concerns the whole South Asia region. They note the persistent 'cultural conservatism' that has survived several turbulent periods, and trace the rich diversity of contemporary wellbeing discourse back to sophisticated ancient Sanskrit texts on wellbeing and virtue. But they also quite rightly note that elite scholarly discourses on 'prescriptive well-being' in Hinduism and Buddhism never tell us much about the everyday experienced wellbeing of ordinary people. For example, it is not how much people's lived experiences were actually influenced by the very strong textual association between wellbeing and theories of afterlife and rebirth, or by the theoretical division of the life course into behaviourally coded stages. As for Islamic populations, however, the authors to assume that - as was also asserted in the chapter on Islam - the pursuit of wellbeing is understood in terms of obedience to religious prescriptions. This fits well with the regional cultural theme of relativity which is discussed: the proper pursuit of wellbeing is relative to 'the time and place of one's birth, place of habitation, occupation, life stage, karma, dharma, and so on' (p.98).

The second South Asia chapter, by economists Vijay Kumar Shrotryia and Krishna Mazumdar, weirdly comes seven chapters later and the two chapters don't refer to one another. Actually the two chapters are very different - the earlier one being on cultural history and this one being about contemporary socio-economic and demographic processes. Like many other chapters, this offers a wealth of basic descriptive detail not all of which is specifically linked to any arguments about wellbeing. Once wellbeing is introduced, half-way through the chapter, the authors follow the editors in defining health, education, income, and subjective wellbeing as wellbeing 'domains', hence neglecting the important distinction between means and ends that ought - surely- to be central to any account of wellbeing. The overall argument, however, convincingly shows that the whole region faces common patterns and challenges for any wellbeing strategy: the combination of lower fertility rates and better health are producing a rapidly aging population which a weak health care infrastructure struggles to cope with, and there is a huge cohort of young working-age people with poor employment prospects who lack social security provision.

In their chapter on Latin America, Mariano Rojas and José García Vega state that what defines Latin America is a shared set of values about wellbeing. The two economists give us a detailed 
account of the history of the region and its objective quality of life, illustrated by provide impressive data on the development of Latin America. For example, in 1900 life expectancy was 29 in Brazil and 25 in Mexico, the two most populous Latin-American countries, while the average life expectancy in Latin America today is 74. There have also been large improvements in literacy and medical care. Despite these changes, Latin America continues to be a very unequal region, where violence, corruption and crime are all too frequent. Interestingly, the subjective wellbeing of people in Latin America is "outstandingly good", both in terms of positive emotions and life satisfaction. Rojas and García Vega attribute this to the importance of close human relationships and the centrality of the family, and they argue that public policy should be sensitive to this and promote wellbeing with a social focus that is congruent with these values.

Chapter 9, by Estes, Land, Michalos, Phillips, and Sirgy (academics in the fields of social policy, sociology, applied philosophy and marketing research) investigates the development of wellbeing in North America, particularly since the end of World War 2. They begin by defining wellbeing as consisting of economic, health, educational, and subjective elements. Economic, health and educational factors are commonly thought of as contributing to wellbeing and not, in and of themselves, elements of wellbeing however. Using these three factors as indicators of wellbeing highlights the still disparate intra- and inter-disciplinary understandings of personal wellbeing. The extensive historical context provided succeeds in establishing the main theme of the chapter; the historic and continuing inequality of wellbeing amongst ethnic minorities (Black African slaves, Native Americans) and women. The comparison of wellbeing amongst subpopulations provides insight into how North American people perceive wellbeing. Overall, a comprehensive overview of the history of North American wellbeing within an economic and social development framework is provided. It is a valued resource for understanding what drives wellbeing and how it has evolved in one of the world's most developed nations.

The chapter on South-East Asia by Mahar Mangahas and Edilberto de Jesus offers a detailed and unavoidably complex but instructive account of the different wellbeing implications of various phases and varieties of colonial influence. The general picture that emerges is that despite horrific violence and bullying associated with pacification, de-colonization, and state-making, the region's wellbeing was greatly enhanced over the longer term through peace-making, economic growth, public health planning, and provision of education and health services. Education, for example, although sometimes treated as an instrument of colonial domination, was often promoted explicitly for the sake of wellbeing. They provide a good overview of indicators relating to contemporary wellbeing, and emphasise that as in most parts of the world, one of the best prospects for improved aggregate wellbeing will be to promote inclusive growth and reduced inequality.

Chapter 13 on Europe, by Wolfgang Glatzer and Jürgen Kohl, is the most contemporary and the most statistically comprehensive chapter of the collection. The overall message is that European history, being uniquely rich in statistical evidence, most clearly illustrates the increasing policy relevance of subjectivity as societies achieve political, material, and socioeconomic progress. Whereas history is replete with evidence of events and processes that we can be sure caused mass misery, since the end of World War II Europe has been increasingly confident of democratic rights, peace, and healthy life expectancy. And in contradiction of the current pervasive tide of cultural pessimism and anti-modernism, they provide clear evidence that most Europeans do not report being lonely, and that loneliness is lowest in northern and western parts of Europe. One of their most interestingly provocative points, although not very clearly expressed (p.449), is that critics who associate the promotion of 'life satisfaction' with selfish hedonism should bear in mind that it is quite likely that most people include empathic 
interest in other people when they evaluate their own lives. This begs an important question that they don't raise, and which challenges their mainly statistical approach: assuming that it matters a great deal how people interpret and respond to survey questions, how can we ever hope to make sense of statistical surveys about wellbeing without a much bigger effort to conduct and synthesise qualitative research that complements the number-crunching?

In chapter 14 on Oceania, by Robert Cummins and Tanja Capic provide a historical overview and discussion of the economic, health, educational and subjective wellbeing dimensions of the people of Oceania's three largest countries, namely Australia, New Zealand, and Papua New Guinea. The main overall story is one of illbeing before colonization, which worsened during and after colonization until things began to improve after World War 2. One contentious claim is that persistent disparities in wellbeing are likely to be made worse by continuing 'success' in modernization (p.457). They don't explain this belief by specifying which inequalities are getting worse, and yet this kind of specification ought to lie at the heart of the assessment and analysis of wellbeing. Several claims are unsubstantiated, some statistics are dated, and there are occasional typos, but they do provide some hard facts in relation to the wellbeing of indigenous populations.

Chapter 15 on the 'transition' countries of the former Soviet Union, by economists Carol Graham and Aurite Werman, looks at what happens to wellbeing when countries move from repressive regimes and planned economies to more democratic government and free markets. The answer is not as clear as many of us might have expected. This is a particularly complex task because, as the authors note, these countries had very different histories before they became communist states: some had been part of Europe and had long experience in market economies and democracy, while others had been rural or nomadic societies. What happened to these countries after the dissolution of the Soviet Union was in large part predicted by this previous history, with Eastern Europe faring better, but they have all had to pay a price in wellbeing during their transitions to democracy and free market economies. In general, subjective wellbeing has followed a V-shaped trajectory over the years: dropping dramatically right after the transition began and partially recovering from around 2005 on, with marked differences between age cohorts (with younger people and those who are better off people adapt better that their older and poorer counterparts). Interestingly, these countries in transition don't show clear signs of the "democracy bonus" on wellbeing that characterizes other democratic countries.

Birger Poppel's chapter on Arctic Peoples is 37 pages long, of which only around $10 \%$ to $20 \%$ is concerned with psychological wellbeing. The rest of the chapter is an excellent overview of the history and development of the Artic region, which does provide context for the psychological wellbeing focus of the last few pages. If you are interested in how the Artic is defined and delimited (e.g., depending on definition this can range from 4 million to 10 million inhabitants) or various issues to do with social, economic, health or climate change, this is a very good resource. Regarding wellbeing however, this chapter suggests that little quality information is available (i.e., a lack of comparable official statistics across regions), but does outline the main results of the current surveys. The general conclusion from current data is as would be expected; indigenous peoples of the Arctic still engage in subsistence activities, suffer from a range of illhealth and ill-being (e.g., high mortality rates, high youth suicide rates), and their psychological wellbeing is lower than non-indigenous populations. As a distinct positive this is the first review available of Artic people's wellbeing. 


\section{Concluding comments}

As an extremely ambitious collection offering encyclopedic coverage of historical and contemporary information relevant to wellbeing worldwide, this is impressive. It will be a useful resource to those who can afford Springer's prices - like some other publishers, they are no longer able to price their books at a level within the budget of most individuals and small libraries. Either as a dip-in resource, or as an information-rich read for those who really want to get a sense of global historical and geo-political patterns of wellbeing, it will make significant contributions to wellbeing scholarship.

\section{Authors}

Neil Thin

University of Edinburgh

n.thin@ed.ac.uk

Margarita Tarragona

PositivaMente \& Grupo Campos Elíseos

Paul Wong

Saybrook University, Trent University and Tyndale University College

Rebecca J. Jarden

Auckland University of Technology

Jonathan Bartholomaeus

South Australian Health and Medical Research Institute

Aaron Jarden

Flinders University \& South Australian Health and Medical Research Institute

\section{Publishing Timeline}

Received 9 June 2017

Accepted 9 June 2017

Published 9 June 2017 